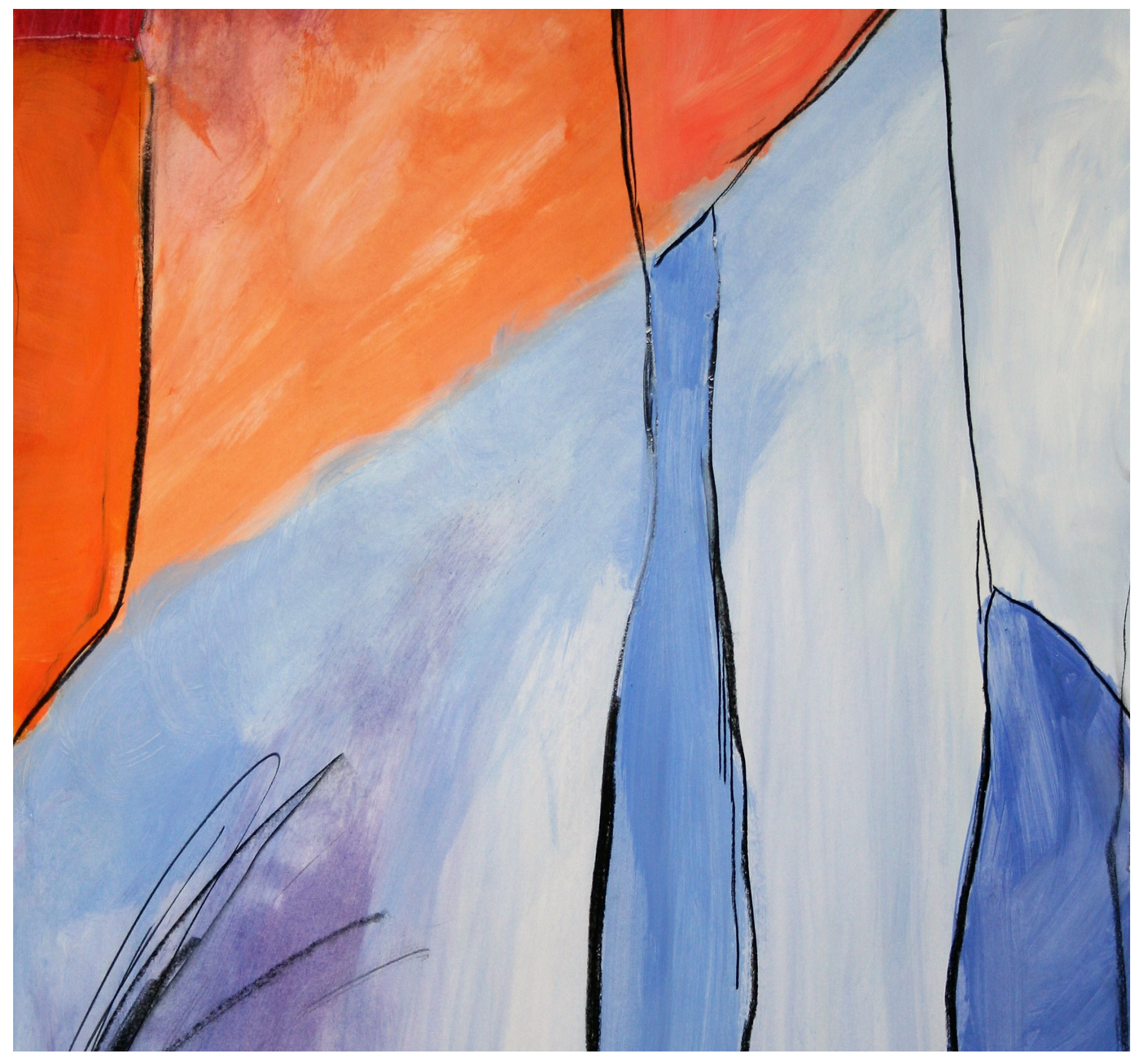

Colour Play I

Acrylic and Pastel

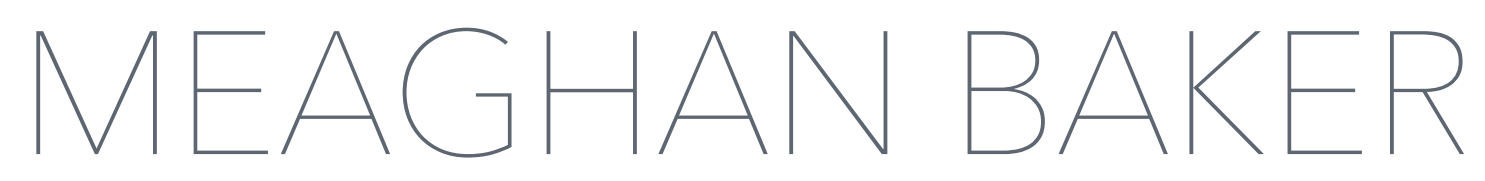

College of Education 


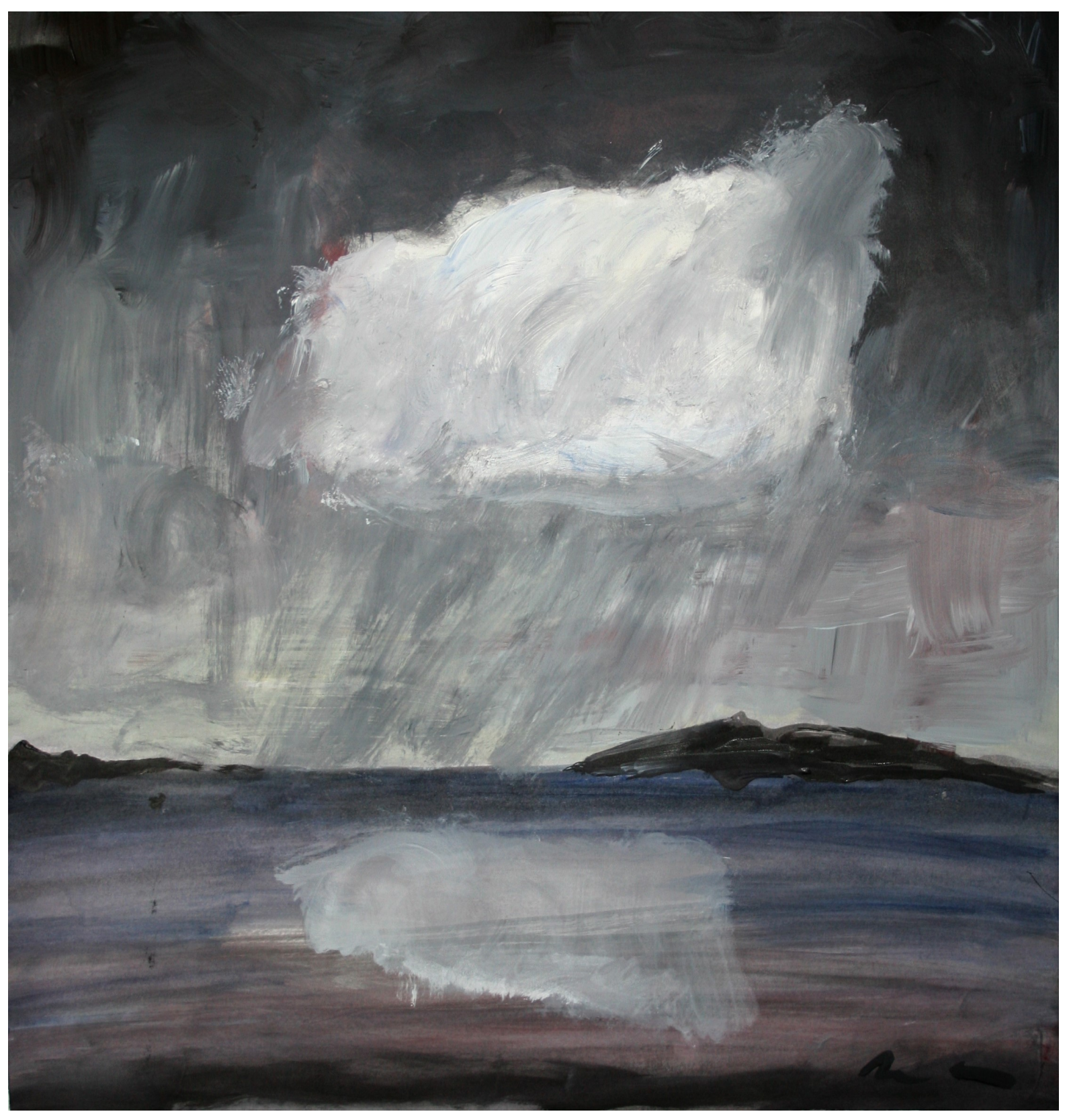

The Cloud

Acrylic 


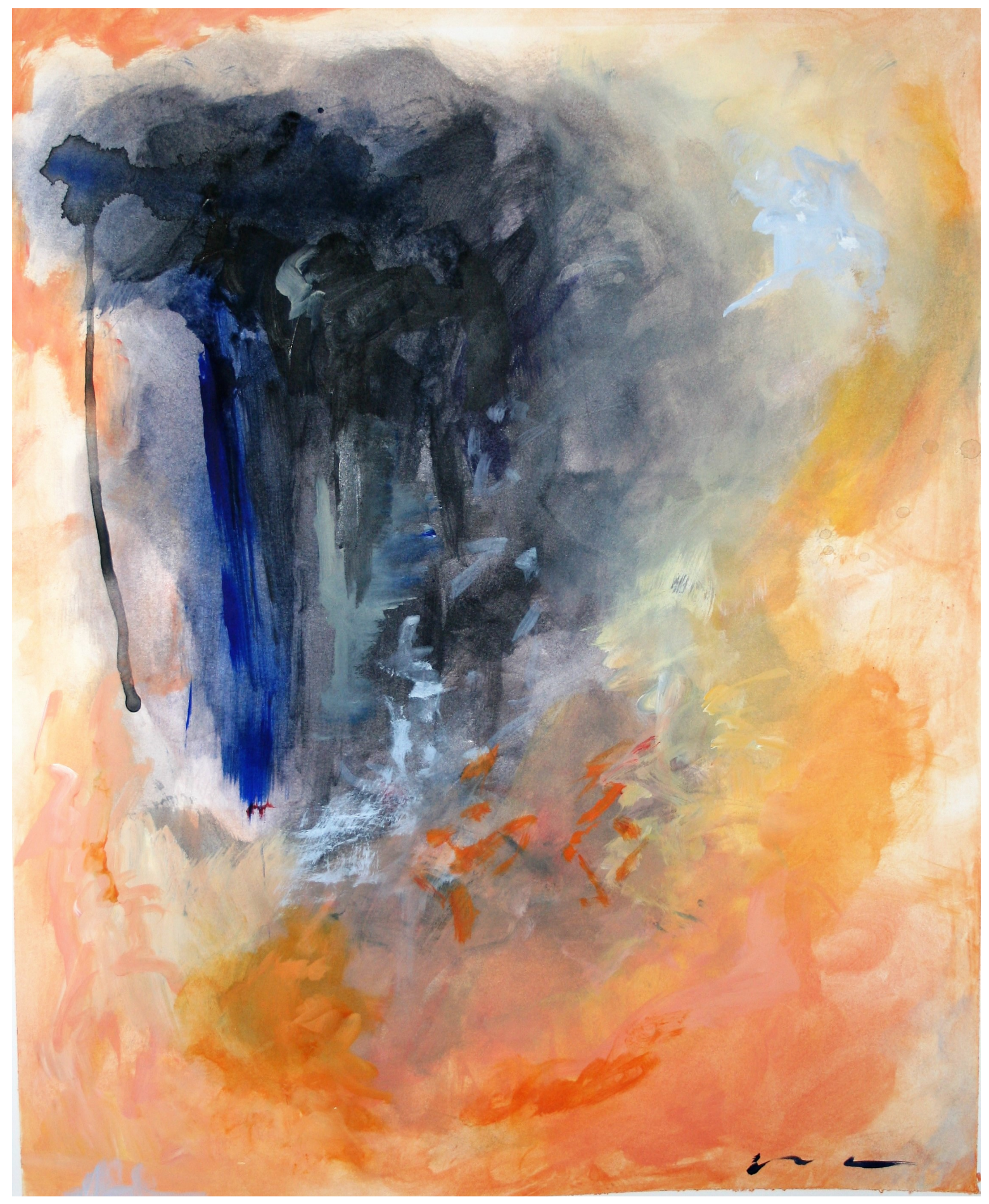

\section{Empty Place}

Acrylic 


\section{Artist's Statement}

For me, art has always primarily been a place to express and process my own experiences. I generally encounter fleeting but strong emotions and, as such, my paintings incorporate elements which are suggestive of this. Namely, I am fond of using expressive brush strokes which are laid down hastily and with moody colour combinations. As of late, I have been experimenting with abstraction using minimal structural planning, allowing the modest structure to become the jungle gym upon which the more emotive elements, like colour, play. Artistic media allows me to translate my emotional experiences into something tangible, something on paper or canvas that I can reflect on and explore further by manipulating the paint, pastel, ink, etc. While my paintings are personal emotional outlets and playgrounds, I hope that my work will create for viewers some kind of emotional encounter which evokes in them some personal reflection and analysis of their own. - 
